\title{
Improving safety in Greek road tunnels
}

\author{
K. Kirytopoulos ${ }^{1}$, A. Rentizelas ${ }^{2}$, I. Tatsiopoulos ${ }^{2}$ \& K. Kazaras ${ }^{2}$ \\ ${ }^{1}$ University of the Aegean, Greece \\ ${ }^{2}$ National Technical University of Athens, Greece
}

\begin{abstract}
Tunnels are regarded as one of the most important infrastructures in Europe, as they may improve the connection of regions and aid economic development through facilitating the transportation of people and goods.

In order to achieve a minimum acceptable level of safety, the EC issued Directive 2004/54/EC, which describes specific safety measures that have to be taken for all road tunnels in the trans-European road network.

In parallel, there are several qualitative or quantitative methods for measuring road tunnel safety, while the method that seems to be the most accepted by administrative authorities for quantitative risk analysis is the OECD/PIARC QRA Model (QRAM), which has been developed by INERIS, WS-Atkins and the Institute for Risk Research. QRAM is based on engineering software that aids quantitatively assessment of the societal risk due to transporting goods and dangerous goods with Heavy Goods Vehicles (HGV) through road tunnels.

The aim of this paper is to expose the effectiveness of the measures imposed by the EC in Greek road tunnels. A typical road tunnel, as designed and implemented after Directive 2004/54/EC, is compared to the same tunnel as if it was developed before the Directive was put into action. The comparison is made on the basis of the societal risk existing in the two cases.

The conclusion of the paper, based on the outcome of the risk analysis with the QRAM method, is that the safety of Greek Tunnels is significantly improved due to the implementation of the measures imposed by the EC Directive 2004/54/EC.
\end{abstract}

Keywords: road tunnel, risk analysis, quantitative analysis, safety, dangerous goods, Greece. 


\section{Introduction}

Road tunnels improve the connection between different regions by minimizing the time needed for travelling from one region to another. This is quite important for both transportation of individuals and goods. Moreover, tunnels may also lead to the economic development of those areas that were previously isolated. However, the increasing number of these important infrastructures is raising upfront an endogenous problem, which is the severity of accidents that may occur. The most important kind of accident in a road tunnels is fire, as it can lead to losses of users and furthermore it may cause significant damage to the infrastructure itself, along with the environment. The problem is amplified when dangerous goods are involved in accidents in road tunnels.

The most important incidents relevant to road tunnels are considered to be the Mont Blanc and Tauern disasters (1999), the Kaprun tragedy (2000), the Gleinalm tunnel fire (2001) and St Gotthard tunnel fire (2001), which caused fatalities and severe traffic restrictions [4].

One of the most severe road tunnel accident until now is the Mont Blanc Tunnel disaster in 1999 which resulted in 39 fatalities and to the closure of the tunnel for three years [6]. Conclusions were that fatal consequences could have been greatly reduced by a more efficient organization of operational and emergency services.

Right after the Mont Blanc Tunnel accident, the Tauern Tunnel disaster came to take place and led to a huge fire catastrophe with 12 fatalities [11]. Two other fires in road tunnels caused a significant number of casualties. The Gotthard Tunnel accident that led to 11 fatalities and the Gleinalm Tunnel accident that resulted in five fatalities [1].

The common characteristic of the aforementioned accidents is that all occurred in long $(>6 \mathrm{~km})$ single bore tunnels. Moreover, apart from the direct impact, these accidents led to traffic congestion in alternative routes and in turn, caused a further rise in accident risks [6] for many months or even years after the disaster.

Due to these and other high impact accidents in road tunnels, the European Commission concluded, after years of consultations, to the Directive 2004/54/EC. The EU Directive entitled "minimum safety requirements for tunnels in the trans-European road network" is today one legislative text of major importance for EU countries, setting basic requirements for tunnels in the Trans-European Road Network. The EU Directive lays down a set of harmonised minimum safety standards dealing with the various organizational, structural, technical and operational aspects. The aim of the EU Directive is to ensure that all tunnels longer than 500 meters, whether in operation, under construction or at the design stage, comply with the new safety requirements.

In order to achieve a minimum acceptable level of safety, the EU Directive suggests, apart from the measures imposed based on tunnel characteristics, the implementation of a risk analysis in cases such as the opening of a road tunnel to dangerous goods. However, the EU Directive does not indicate either the method for performing the risk analysis or the criteria for risk acceptance. Thus, each 
country/administrative authority or even each tunnel manager may select the appropriate method of analysis as well as the criteria for risk acceptance. The method that seems to be the most widely accepted by administrative authorities for quantitative risk analysis is the OECD/PIARC QRA Model (QRAM). The QRAM not only assesses the risks from the transportation of dangerous goods in a quantitative way but it also evaluates the effect of the mitigation measures carried out in a specific road tunnel [17].

The research problem that this paper addresses is the improvement of safety in Greek road tunnels due to the adoption of the EU Directive. The research is based on the comparison of the societal risk existing in a typical road tunnel designed and implemented after the EU Directive to the societal risk existing in the same tunnel as if it was developed before the Directive was put into action. The method used in this work regarding the quantitative risk analysis and the societal risk assessment is the aforementioned QRAM.

The rest of this paper is structured as follows. The second section presents the literature review for risk analysis in road tunnels and the use of QRAM. The third section provides information about the evolutions in the operational safety of Greek road tunnels whereas the fourth section is divided in two subsections dealing with the pilot case description and the QRAM results. The paper concludes with a discussion section which summarises the findings and makes some suggestions for further research.

\section{Literature review}

Risk management entails the processes of risk identification, analysis, mitigation and follow up and for each process a set of potential tools exist to aid risk managers in their work [12]. Specifically for risk analysis, simulation is one of the mostly used tools $[16,18]$. Risk analysis methods were initially developed quantitatively in the nuclear industry in the early 1970's [15]. After two severe accidents with hazardous materials in chemical plants (Bhopal, Seveso) the risk analysis methods were adjusted to chemical plants in the late 1970's [2].

In the context of transport, quantitative risk analysis was initially applied to transportation of hazardous materials and later to all transport. The fundamental steps in the risk analysis methods for these different applications are the same and involve the description of the system, the identification of hazards and the assessment of the frequency as well as the consequences of each hazard.

Risk analysis for road tunnels produces a quantified risk expressed as an individual risk and a societal risk arising from the public's aversion to high numbers of fatalities in a single accident [8]. A broad range of quantitative methods are available, thus the choice of the methods should be done by considering the respective advantages/disadvantages in the context of a specific situation [14].

However, one of the most widely accepted quantitative methods for measuring road tunnel safety is the QRAM that has been developed by INERIS, WS-Atkins and the Institute for Risk Research. The aim of the QRAM is to quantify the risks due to transport of dangerous goods on given routes of the road 
system. A complete assessment of the risks involved in transporting dangerous goods would require consideration of all kinds of dangerous materials and other general variables such as meteorological conditions. As the coverage of all circumstances is very difficult in practice, simplifications are made. Thus, the QRAM considers 13 accident scenarios. These accident scenarios (namely HGV fire $20 \mathrm{MW}$, HGV fire $100 \mathrm{MW}$, BLEEVE of LPG in cylinder, motor spirit pool fire, VCE of motor spirit, chlorine release, BLEEVE of LPG in bulk, VCE of LPG in bulk, torch fire of LPG in bulk, ammonia release, acrolein in bulk release, acrolein in cylinders release, BLEEVE of carbon dioxide in bulk) are representative of the groupings of dangerous goods as described in the proposed regulations of PIARC [13] and have been chosen to examine different severe effects such as overpressure, thermal effect and toxicity [9]. The QRAM methodology is based on the following steps [17].

1. Choice of a restricted number of dangerous goods

2. Choice of representative accidental scenarios implying those dangerous goods

3. Identification of physical effects of those scenarios for a tunnel section

4. Evaluation of their physiological effects on road users and on the local population taking into account the possibilities of escape/sheltering

5. Determination of yearly frequency of occurrence and relevant number of fatalities (+injuries) for each scenario

The most important inputs of the model include:

a) The infrastructure of the tunnel

b) The mechanical and electrical installations of the tunnel

c) Traffic data

The outcome of the Model is the Individual Risk as well as the relevant F/N curves for fatalities and injuries [7]. F/N curves present graphically the frequency (F) of accidents with $\mathrm{N}$ or more victims, where $N$ ranges upward from 1 to the maximum possible number of victims in the system [5]. The evaluation of the tunnel based on the F/N curves provided by the Model is usually made either on a comparative basis (comparison to alternative routes) or according to the positioning of the $\mathrm{F} / \mathrm{N}$ curves compared to a threshold of non-tolerable risk. In this work, the safety of the examined tunnels is evaluated with respect to one another option.

The version of the Model used in this work is the currently latest QRAM-DG 3.61 version. The model consists of spreadsheet-based tools and a Fortran program for some finer results. It is aimed at being simple to use, but experts may make changes to take account of specific situations or data [10]. The Model is already used in several European Countries [14] whereas in Greece, the use of the QRAM has been proposed by the Greek tunnel administrative authority as the most suitable method for risk analysis when transportation of dangerous goods is allowed through a tunnel. However, the proposal is still under approval process by the State.

It must be mentioned that the literature concerning the use of the QRAM is not as extensive as one would expect, compared to the extent of its use. Most publications relevant to the QRAM refer to case studies. Thus, the research gap 
identified here is that the evaluation of the effectiveness of the measures imposed by the EU Directive in the trans-European road network for the transportation of dangerous goods has not been studied as a standalone issue. It should be noted here that HGVs that do not carry dangerous goods but may lead to significant fires (greater than 20MW) when involved in an accident are taken into consideration by the QRAM. In this study only these types of HGV will be taken into account, thus the typical dangerous goods are excluded. This option has been followed so that this research could investigate the improvement in Greek road tunnels by the enforcement of the EU Directive even for cases where dangerous goods vehicles (DGVs) are not allowed in a tunnel. The improvement when DGVs are allowed in a tunnel is expected to be even broader.

\section{Evolutions in the operational safety of Greek road tunnels}

The last decade many new roads and highways have been constructed, with many long tunnels due to the mountainous Greek terrain. In fact, Greece will be ranked fourth among EU-15 members in number of tunnels with length greater than $500 \mathrm{~m}$ after the year 2010; therefore, it is only natural that the safety of road tunnels is an issue of crucial importance.

Table 1: $\quad$ Minimum safety measures enforced by the EU Directive.

\begin{tabular}{cccccc}
\hline Classes & Class 1 & Class 2 & Class 3 & Class 4 & Class 5 \\
\hline & $\operatorname{Tr}<2000$ & $\operatorname{Tr}<2000$ & $\operatorname{Tr}>2000$ & $\operatorname{Tr}>2000$ & $\operatorname{Tr}>2000$ \\
$\begin{array}{c}\text { Corresponding } \\
\text { 2004/54/EC category }\end{array}$ & $500<L<1000$ & $L>1000$ & $500<L<1000$ & $1000<L<3000$ & $L>3000$
\end{tabular}

\begin{tabular}{|c|c|c|c|c|c|c|}
\hline Structural & Emergency exits & $\mathrm{N}$ & $\mathrm{N}$ & Every $500 \mathrm{~m}$ & Every $500 \mathrm{~m}$ & Every $500 \mathrm{~m}$ \\
\hline & $\begin{array}{l}\text { Cross-connections for } \\
\text { emergency services }\end{array}$ & $\mathrm{N}$ & Every $1500 \mathrm{~m}$ & $\mathrm{~N}$ & Every $1500 \mathrm{~m}$ & Every $1500 \mathrm{~m}$ \\
\hline & Control centre & $\mathrm{N}$ & $\mathrm{N}$ & $\mathrm{N}$ & $\mathrm{N}$ & $\mathrm{Y}$ \\
\hline Monitoring & Video & $\mathrm{N}$ & $\mathrm{N}$ & $\mathrm{N}$ & $\mathrm{N}$ & $\mathrm{Y}$ \\
\hline & $\begin{array}{lr}\text { Automatic } & \text { Incident } \\
\text { detection/ } & \text { fire } \\
\text { detection } & \end{array}$ & $\mathrm{Y}$ & $\mathrm{Y}$ & $\mathrm{Y}$ & $\mathrm{Y}$ & $\mathrm{Y}$ \\
\hline Ventilation & $\begin{array}{l}\text { Mechanical } \\
\text { Ventilation }\end{array}$ & $\mathrm{N}$ & $\mathrm{N}$ & $\mathrm{N}$ & $\mathrm{Y}$ & $\mathrm{Y}$ \\
\hline $\begin{array}{l}\text { Equipment } \\
\text { to close the } \\
\text { tunnel }\end{array}$ & $\begin{array}{l}\text { Traffic signals before } \\
\text { entrance }\end{array}$ & $\mathrm{N}$ & $\mathrm{Y}$ & $\mathrm{N}$ & $\mathrm{Y}$ & $\mathrm{Y}$ \\
\hline & $\begin{array}{l}\text { Traffic signals inside } \\
\text { tunnel }\end{array}$ & $\mathrm{N}$ & $\mathrm{N}$ & $\mathrm{N}$ & $\mathrm{N}$ & $\mathrm{Y}$ \\
\hline & $\begin{array}{l}\text { Radio re-broadcasting } \\
\text { for } \quad \text { emergency } \\
\text { services }\end{array}$ & $\mathrm{N}$ & $\mathrm{N}$ & $\mathrm{N}$ & $\mathrm{Y}$ & $\mathrm{Y}$ \\
\hline
\end{tabular}


The EU Directive of 2004 changed deeply the way road tunnels are constructed in Greece. The mitigation measures of a new tunnel as required by the EU Directive are described in Table 1.

However, it has been noticed that all the new tunnels built in Greece after the enforcement of the EU Directive are designed and equipped with much more safety features than required. It is indicative that a typical design consists of twin bore (uni-directional) tunnels with two lanes per tube and the typical characteristics showed in Table 2. On the contrary, the majority of Greek road

Table 2: $\quad$ Main characteristics of the tunnels examined.

\begin{tabular}{|c|c|c|c|}
\hline Cases & & $\begin{array}{l}\text { Case } 1 \\
\text { (old specifications) }\end{array}$ & $\begin{array}{l}\text { Case } 2 \\
\text { (new specifications) }\end{array}$ \\
\hline \multirow{6}{*}{$\begin{array}{l}\text { Construction } \\
\text { data }\end{array}$} & Length (m) & 1500 & 1500 \\
\hline & Type & Single-bore & Twin-bore \\
\hline & Lanes (per direction) & 1 & 2 \\
\hline & Gradient & $0 \%$ & $0 \%$ \\
\hline & Camber & $2,50 \%$ & $2,50 \%$ \\
\hline & $\begin{array}{l}\text { Width }(\mathrm{m}) \\
\text { Open cross-sectional area } \\
\left(\mathrm{m}^{2}\right)\end{array}$ & $\begin{array}{l}9,5 \\
66\end{array}$ & $\begin{array}{l}9,5 \\
66\end{array}$ \\
\hline \multirow{4}{*}{$\begin{array}{l}\text { Structural } \\
\text { measures }\end{array}$} & Emergency exits & 2 (every $500 \mathrm{~m}$ ) & 3 (every $375 \mathrm{~m}$ ) \\
\hline & $\begin{array}{l}\text { Cross-connections for } \\
\text { emergency services }\end{array}$ & $\mathrm{N}$ & $\mathrm{N}$ \\
\hline & Drainage open area $(\mathrm{m} 2)$ & 0,08 & 0,08 \\
\hline & Drainage interval $(\mathrm{m})$ & 75 & 25 \\
\hline \multirow{4}{*}{$\begin{array}{l}\text { Monitoring } \\
\text { systems }\end{array}$} & Control centre & $\mathrm{N}$ & $\mathrm{Y}$ \\
\hline & Video & $\mathrm{N}$ & Y \\
\hline & $\begin{array}{l}\text { Automatic Incident } \\
\text { detection and/or fire } \\
\text { detection }\end{array}$ & $\mathrm{Y}$ & $\mathrm{Y}$ \\
\hline & $\begin{array}{l}\text { Emergency } \\
\text { communications }\end{array}$ & $\mathrm{Y}$ & $\mathrm{Y}$ \\
\hline \multirow[t]{3}{*}{ Ventilation } & Mechanical Ventilation & $\mathrm{N}$ & $\mathrm{Y}$ \\
\hline & Normal Operation $\left(\mathrm{m}^{3} / \mathrm{s}\right)$ & 0 & 160 \\
\hline & Emergency operation $\left(\mathrm{m}^{3} / \mathrm{s}\right)$ & 0 & 220 \\
\hline \multirow{4}{*}{$\begin{array}{l}\text { Equipment to } \\
\text { close the } \\
\text { tunnel }\end{array}$} & $\begin{array}{l}\text { Traffic signals before } \\
\text { entrance }\end{array}$ & $\mathrm{N}$ & $\mathrm{Y}$ \\
\hline & Traffic signals inside tunnel & $\mathrm{N}$ & $\mathrm{Y}$ \\
\hline & $\begin{array}{l}\text { Radio re-broadcasting for } \\
\text { emergency services }\end{array}$ & $\mathrm{N}$ & $\mathrm{Y}$ \\
\hline & Time to stop traffic (min) & 180 & 5 \\
\hline
\end{tabular}


Table 3: $\quad$ Detailed traffic-related data.

\begin{tabular}{lc}
\hline Traffic-related data & \\
\hline HGV traffic (\% of total traffic) & 9 \\
Bus traffic (\% of total traffic) & 1,5 \\
Average number of persons in a car & 1,85 \\
Average number of persons in a HGV & 1.17 \\
Average number of persons in a bus/coach & 40 \\
\hline
\end{tabular}

tunnels in the past were bi-directional single bore tunnels with two lanes in total for both directions, equipped with neither mechanical ventilation, nor monitoring systems. Typical paradigms are the Vrachassi road tunnel in Crete, the Aetos tunnel in Arta and many others. Even in long tunnels with length more than $1000 \mathrm{~m}$ and dense traffic volume the design and construction characteristics were similar to the aforementioned. Typical example of such a case was the tunnel of Artemissio in Peloponnesus.

\section{Case study}

\subsection{Pilot case description}

The aim of the research is to expose the effectiveness of the measures imposed by the EU Directive of 2004 in Greek road tunnels. A typical road tunnel as designed and constructed after the EU Directive is compared to the same tunnel as if it was developed before the EU Directive was put into action. In Table 2 the main characteristics of both typical tunnels examined is presented.

The comparison of the safety of the two typical tunnels is made regarding their societal risk for three different traffic volumes. The first is 5000 vehicles/day, the second is 9000 vehicles/day and the last is 15000 vehicles/day. Table 3 shows detailed traffic-related data that are common for the three traffic volume scenarios.

This paper explores the safety of typical tunnels and not specific existing ones. Since the transportation of dangerous goods is forbidden in the majority of Greek road tunnels up to now, consideration is taken only for HGVs that do not carry dangerous goods but may lead to large fires, and therefore calculations are performed only for scenario 1 and scenario 2 of the QRAM.

\subsection{QRA model results}

The following charts show the results of the QRAM for the three cases examined. In each chart the F/N curve of the "old" type of tunnel is compared to the $\mathrm{F} / \mathrm{N}$ curve of the "new" type of tunnel, according to the assumed traffic volume.

For traffic volume 5000 vehicle/day (case 1) for the typical tunnel with the old specifications, the expected value (fatalities+injuries per year) is $1,285 \mathrm{E}^{-2}$ whilst for the tunnel with the new specifications it is $1,344 \mathrm{E}^{-3}$. By this yardstick 
the level of safety of the "new" tunnel is almost 10 times (one grade of magnitude) higher than that of the "old" tunnel. As shown in Figure 1, the F/N curve of the new type tunnel lays well below the F/N curve of the old type for any given number of victims. Additionally, the maximum number of victims for the new type of tunnels is less than seven whereas for the old type may lead to more than 15 victims.

In case 2, traffic volume is assumed to be 9000 vehicles/day. For the typical tunnel with the old specifications the expected value (fatalities+injuries per year) is $2,646 \mathrm{E}^{-2}$ while for the tunnel with the new specifications is $4,08 \mathrm{E}^{-3}$. By this yardstick the level of safety of the "new" tunnel is almost 6,5 times higher than that of the "old" tunnel. As shown in Figure 2, the F/N curve of the new type tunnel lays well below the $\mathrm{F} / \mathrm{N}$ curve of the old type for any given number of victims. Additionally, the maximum number of victims for the new type of tunnels is almost 12 whereas for the old type may lead to more than 25 victims.

Lastly, for traffic volume 15000 vehicles/day (case 3), for the typical tunnel with the old specifications the expected value (fatalities+injuries per year) is calculated as $5,325 \mathrm{E}^{-2}$, while for the tunnel with the new specifications it is $1,074 \mathrm{E}^{-2}$. By this yardstick the level of safety of the "new" tunnel is about 5 times higher than the "old" tunnel. As shown in Figure 3, the F/N curve of the new type tunnel lays well below the F/ $\mathrm{N}$ curve of the old type up to 14 victims. For a number of victims ranging between 15 and 19 there is the same probability for both the "new" and the "old" tunnel. However, the maximum number of victims for the new type of tunnels is 19 whereas for the old type may lead to more than 40 victims.

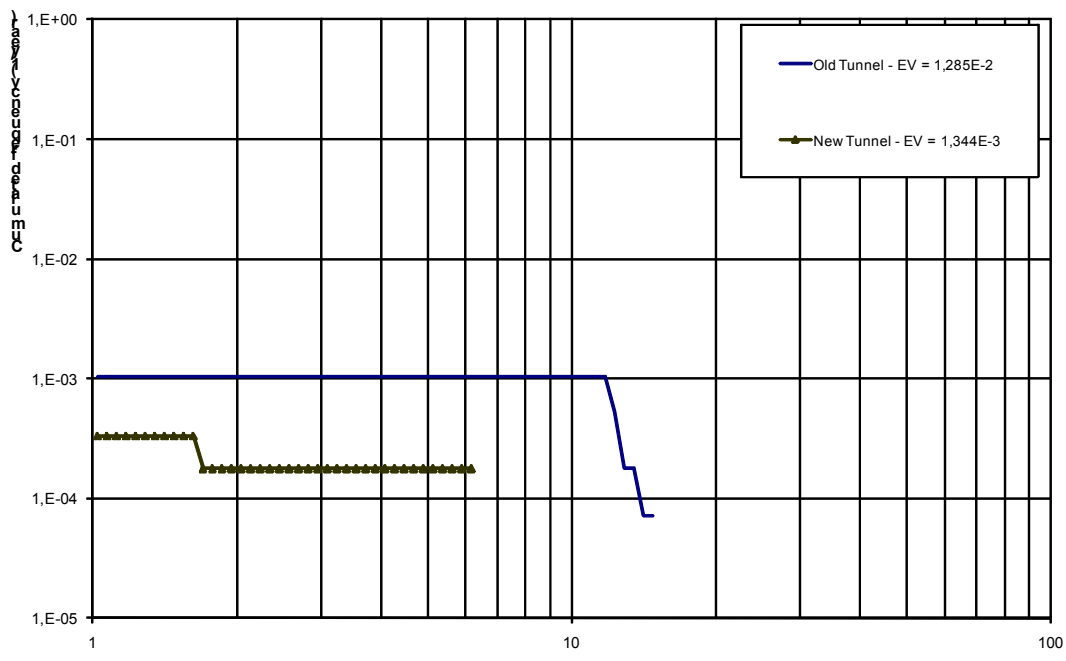

$\mathrm{EV}=$ Expected Value $=$ Fatalities $(+$ Injuries $) /$ year

Figure 1: $\quad$ Safety level comparison for traffic, 5000 vehicles/day. 


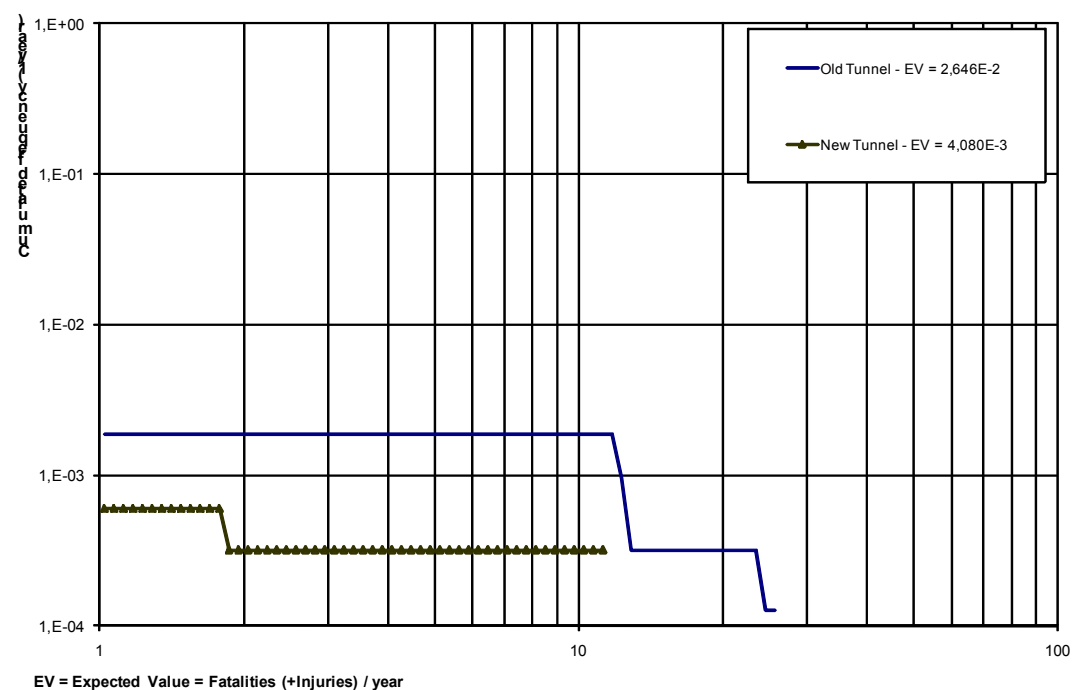

Figure 2: Safety level comparison for traffic, 9000 vehicles/day.

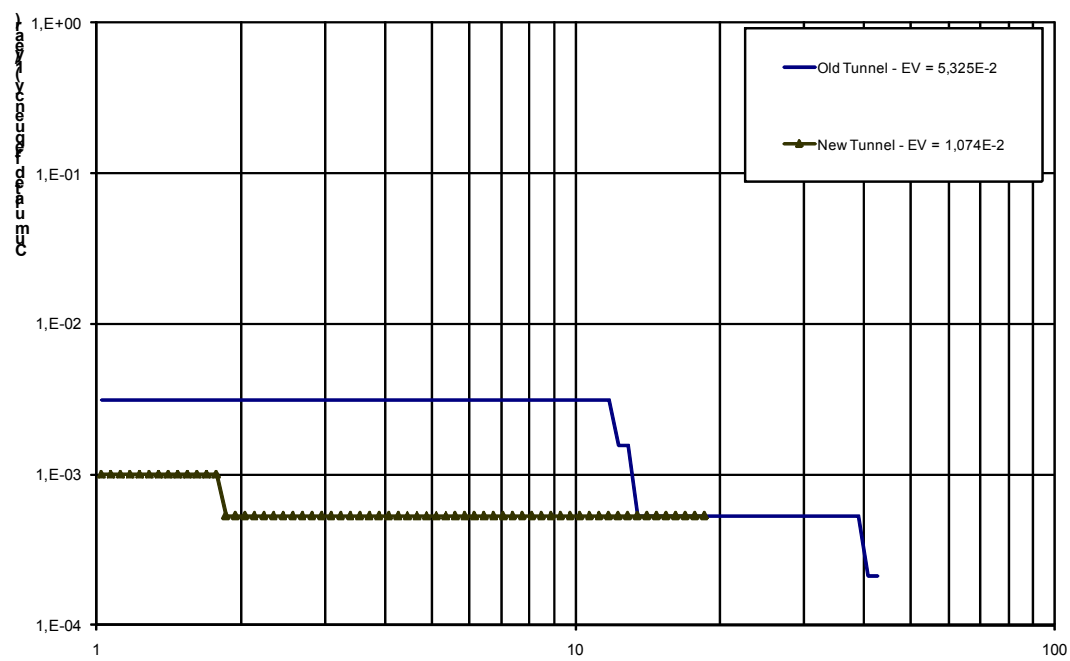

$\mathrm{EV}=$ Expected Value $=$ Fatalities $(+$ Injuries $) /$ year

Figure 3: $\quad$ Safety level comparison for traffic, 15000 vehicles/day. 


\section{Conclusions and further research}

For all the examined cases the typical Greek tunnel designed or/and constructed after the adoption of the EU Directive has a higher level of safety than the same tunnel as if it was constructed before the implementation of the Directive. It is therefore deduced that the safety measures imposed by the EU significantly improved the safety of Greek road tunnels.

Although the implementation of the EU Directive seems to improve the safety level of road tunnels in the trans-European road network, an interesting further investigation would be to explore the sufficiency of the minimum tunnel safety measures imposed by the EU Directive. Another controversial area for further investigation is whether the traditional way of risk assessment is sufficient for human-technical systems such as road tunnels. Traditional risk assessment techniques are neither dynamic nor systemic enough to cope with the danger arising from humans' actions in such systems. The investigation of new risk assessment techniques in human technical systems would therefore have great scientific interest.

\section{References}

[1] Carvel, R., Beard, N., Jowitt, W. and Drysdale, D., Fire Size and Fire Spread in Tunnels with Longitudinal Ventilation Systems, Journal of Fire Sciences 23, 485-518, 2005.

[2] COVO, Risk analysis of six potentially hazardous industrial objects in the Rijnmond area, Dordrecht Reidel, 1982.

[3] EC, Directive on minimum safety requirements for tunnels in the transEuropean road network, Official Journal of the European Union, L 167, 2004.

[4] European Thematic Network Fire in Tunnels, Fire in Tunnels General Report, WTCB, Brussels, Belgium, 2007

[5] Evans, A., Transport fatal accidents and FN-curves 1967-2001, Research report 073 for the Health and Safety Executive, University College London, UK, 2003.

[6] Haack, A., Current safety issues in traffic tunnels, Tunnelling and Underground Space Technology, 17, 117-127, 2002.

[7] INERIS, Transport of Dangerous goods through road tunnels Quantitative Risk Assessment Model (v. 3.60 and v. 3.61) Reference Manual, Verneuilen-Halatte, France, 2005.

[8] Khoury, G.A and Molag, M., Actual time tunnel safety-A new approach, Tunnels and Tunnelling International, pp 46-48, 2005.

[9] Knoflacher H., Pfaffenbichler P.C. and Nussbaumer H., Quantitative Risk Assessment of Heavy Goods Vehicle Transport through Tunnels - the Tauerntunnel Case Study, $1^{\text {st }}$ International Conference Tunnel Safety and Ventilation, Graz, 2002.

[10] Lacroix, D., Cassini, P., Hall, R. and Saccomanno, F., Transport of dangerous goods through road tunnels: an integrated qra model developed 
under the joint oecd/piarc project ERS2, International ESReDA Seminar, Oslo, 1999.

[11] Leitner, A., The fire catastrophe in the Tauern Tunnel: experience and conclusions for the Austrian guidelines, Tunnelling and Underground Space Technology, 16, 217-223, 2001.

[12] Leopoulos, V., Kirytopoulos, K., and Malandrakis, C., Risk management for SMEs: Tools to use and how, Production Planning and Control 17 (3), 322-332, 2006.

[13] OECD, Safety in tunnels - Transport of dangerous goods through road tunnels, Organization for Economic Co-operation and Development OECD Publications, Paris, 2001.

[14] PIARC, Risk analysis for road tunnels, World Road Association (PIARC), France, 2008.

[15] Rasmussen, NC., Reactor Safety Study, Nuclear Regulatory Commission Document WASH-1400, NUREG 75/014, 1975.

[16] Rentizelas, A., Tziralis, G., Kirytopoulos, K., Incorporating uncertainty in optimal investment decisions, World Review of Entrepreneurship, Management and Sustainable Development 3 (3-4), 273-283, 2007

[17] SAFE-T, Appendix 1: Tools for Probabilistic risk assessment, SAFE-T research project report, 2008.

[18] Tziralis, G., Kirytopoulos, K., Rentizelas, A. and Tatsiopoulos, I., Holistic investment assessment: Optimization, risk appraisal and decision making, Managerial and Decision Economics 30 (6), 393-403, 2009. 